\title{
El derecho a la educación en tiempos de COVID19
}

\section{The right to education in times of COVID19}

\author{
Juan Alberto Rojas-Cárdenas \\ up.juanrojas@uniandes.edu.ec \\ Universidad Regional Autónoma de los Andes, Puyo \\ Ecuador \\ https://orcid.org/0000-0001-9026-4402 \\ Jocelyne Jamilex Cambal-Condo \\ dp.jocelynejcc82@uniandes.edu.ec \\ Universidad Regional Autónoma de los Andes, Puyo \\ Ecuador \\ https://orcid.org/0000-0002-7329-0753 \\ Jonathan Rojas-Armijos \\ dp.jonathanara59@uniandes.edu.ec \\ Universidad Regional Autónoma de los Andes, Puyo \\ Ecuador \\ https://orcid.org/0000-0001-7234-3174
}

Recepción: 15 de septiembre 2021

Revisado: 25 octubre 2021

Aprobación: 15 de noviembre 2021

Publicación: 01 de diciembre 2021 


\section{Estimado Editor (a):}

Desde el inicio de los tiempos las universidades se enfrentaron a diversas situaciones, las cuales afectaron a su normal funcionamiento como por ejemplo en 1965 la universidad de Cambridge tuvo que cerrar por la epidemia de la peste negra que llegó a Inglaterra, sin embargo, la educación superior siguió su ritmo debido que la formación profesional es de vital importancia para la sociedad. Actualmente el Covid19 llegó al país a causar el mismo efecto, así como en todo el mundo, por tal motivo se optó por la educación virtual, así como hubo varios impactos en la economía, la salud, entre otros, es por eso que la presente investigación se enfocará en determinar las consecuencias que se obtuvo y a la vez se dará alternativas para mejorar la educación superior en tiempos de pandemia.

En este orden de ideas, el gobierno ecuatoriano se vio obligado a disponer medidas de confinamiento, que causo el cierre permanente de escuelas y colegios, a fin de evitar la propagación del virus. En este orden de ideas, mediante Decreto Presidencial No. 1017 con fecha 17 de marzo de 2020, se declaró a la República del Ecuador en Estado de Emergencia.

Durante la pandemia se dio paso a la utilización de herramientas y recursos tecnológicos con el fin de mantener el sistema educativo, y se pasó de la educación presencial a la educación virtual. Sin embargo, muchas universidades han tenido retos para la adaptación de la misma, dando como resultados positivos y negativos en la educación superior.

La pandemia del virus Covid-19, lamentablemente se llevó consigo muchas vidas humanas de diversa edad, para evitar que el virus se expanda se tuvo que realizar cuarentena obligatoria y lo cual nuestro estilo de vida cambió, se puede apreciar aun como la educación superior cambio de modalidad presencial a ser únicamente virtual, se suponía que inicialmente esta modalidad duraría 3 semanas, sin embargo la situación actual después de un año y tres meses aún se sigue viviendo la misma problemática, es de conocimiento general que el nivel de educación virtual es deficiente en comparación al nivel de educación presencial, esto es provocado por diversos factores como, la mala conexión a internet que se tiene en la mayor parte del país y/o las pocas oportunidades de acceder a la misma, los recursos económicos no 
permite al estudiante obtener unos dispositivos para su aprendizaje y muchas veces la ausencia del docente deja vacíos en los estudiantes, la falta de conocimiento al manejar las plataformas virtuales tanto de parte del docente como del estudiante. En este sentido, para Bembibre (2012) indica:

Se entiende por educación universitaria a aquel tipo de educación superior que se lleva a cabo cuando la persona ha terminado la educación básica y secundaria. Este tipo de educación se caracteriza además por la especialización en una carrera, lo cual significa que ya no se comparten conocimientos comunes en todo el grupo etario, sino que cada uno elige una carrera particular donde se especializará sobre algunos conocimientos (por ejemplo, conocimientos de política, de abogacía, de medicina, de idiomas, de lenguaje, de historia, de ciencia, etc.).(p.3)

Por consiguiente, se puede decir que la educación superior coopera en el desenvolvimiento ante el entorno personal y es un método de superación encaminado a conseguir objetivos claros, precisos, concisos. Entonces a nivel superior, este ayuda a Establecer bases que fortalecen la personalidad y claramente para mejorar las habilidades en el ámbito laboral. Al igual que otras crisis de salud, la pandemia del coronavirus (COVID19) enfrenta problemas importantes en la vida de las personas, incluida la educación. En este caso, la educación, reeducación individual y grupal se enfrenta a un caso natural en el que no se está debidamente capacitado y se carece de información. La educación rápida, tanto personal como socialmente, es un desafío que todos enfrentan.

Con esto se puede decir que las clases virtuales es un término muy conocido en la educación y que presenta muchos beneficios y oportunidades para el estudiante en tiempos como ahora que se dio por el COVID-19, está nueva modalidad requiere de mucha disciplina y ofrece oportunidades a los alumnos mediante plataformas digitales para continuar con el estudio. Es claro que durante este periodo de pandemia los estudiantes no han aprendido de la misma manera en que lo hacían cuando asistían a las aulas de clase, aunque es claro que todos los aparatos tecnológicos son de gran ayuda en el aprendizaje.

Es así que se puede deducir que las dificultades que han tenido las universidades son las siguientes: Desigualdades socioeconómicas: La transición a la educación en línea ha revelado las disparidades socioeconómicas que existen en el país. Especialmente 
en las provincias alejadas de la capital, muchos estudiantes no tienen Internet o no tienen las herramientas técnicas para acceder a clases virtuales, es por eso que se ha sentido la baja de los estudiantes en las instituciones. Falta de habilidades técnicas y métodos necesarios para la educación en línea: El cambio a la educación en línea y la seguridad médica ha sorprendido a los docentes universitarios. Para hacer realidad el aula virtual, los docentes deben adaptar e implementar de inmediato nuevas herramientas de enseñanza. Sin embargo, debido al rápido desarrollo de la educación, se encuentra que muchos docentes carecen de las habilidades digitales que necesitan para llegar a sus estudiantes de manera efectiva.

Las universidades que ya iniciaron la transición a la digitalización antes de la pandemia y cuentan con la infraestructura tecnológica tienen cierta experiencia en el desarrollo de una cultura digital, estudiantes y docentes universitarios se adaptaron a través de mecanismos como procesos de digitalización y en cuanto al contenido del programa híbrido y en línea. Sin embargo, no pudieron llegar a cubrir con todos los desafíos que se presentaron a lo largo del desarrollo de las clases virtuales. En este sentido, Centeno Caamal (2021), indicó que los maestros no estaban preparados para desarrollar la gestión pedagógica, es decir la enseñanza con soporte de tecnología digital, pues carecen de competencias digitales y a eso se suma el estrés generado por el contexto de pandemia.

Para continuar con los estudios superiores las universidades crearon protocolos que fueron emitidos por los ministerios de educación y ministerios de salud, la educación universitaria siguió de manera online, sin embargo la vida universitaria va más allá de estar en las aulas de manera presencial, el ámbito social educativo se vio afectado casi en su totalidad, el intercambio de experiencias es nulo ya que es muy poca la relación que se mantiene entre compañeros e incluso entre docente y alumno, siendo así que en algunos casos los alumnos no han conocido físicamente a los docentes que imparten las distintas materias. Para Copari Romero (2014)

La enseñanza tradicional como la virtual presenta fortalezas y debilidades, que son intrínsecas a cada una de ellas. La enseñanza tradicional permite el contacto humano entre docente y estudiantes, las clases temáticas se tratan con mayor profundidad y una retroalimentación inmediata. Por otro lado, la educación virtual le faculta al alumno profundizar más en los 
aspectos que le son de su interés, romper barreras de espacio y de tiempo al momento de recibir la clase. $(p, 15)$

Existen varias alternativas desde la perspectiva del estudiante universitario para mejorar la calidad de la educación virtual, como por ejemplo se puede mencionar clases sincrónicas añadiendo una retroalimentación por parte del docente, al igual que dando uso a la cafetería virtual que da acceso la plataforma universitaria, ya que, muchos estudiantes no tienen conocimiento sobre su utilización porque esta herramienta ha sido creada para interactuar entre el docente y estudiante sobre temas extracurriculares con el fin de conocerse como se lo hacía usualmente en clases presenciales; otra alternativa que se pudo observar es que debido a la falta de conectividad por parte tanto de los estudiantes como de los docentes las clases impartidas siempre deberían ser grabadas para el uso de cualquiera de las partes en cualquier momento.

\section{FINANCIAMIENTO}

No monetario.

\section{AGRADECIMIENTO}

A la Universidad Regional Autónoma de los Andes, Puyo, por motivar el desarrollo de la Investigación.

\section{REFERENCIAS CONSULTADAS}

Asamblea Nacional Constituyente de la República del Ecuador, (2008). Constitución de la República del Ecuador. [Constitution of the Republic of Ecuador]. Montecristi. Registro Oficial 449 de 20-oct-2008. Recuperado de https://n9.cl/sia

Bembibre, C. (2012). Defincion de Educación Universitaria. [Definition of University Education].DefinicionABC.Recuperado:de: https://n9.cl/bd070

Centeno Caamal, R. (2021). Formación Tecnológica y Competencias Digitales Docentes. [Technological Training and Teaching Digital Competences]. Revista Tecnológica Educativa Docentes 2.0, 11(1), 174-182. https://doi.org/10.37843/rted.v11i1.210 
Copari Romero, F. (2014). La Enseñanza Virtual en el Aprendizaje de los Estudiantes del Instituto Superior Tecnológico Pedro Vilcapaza- Perú. [ Virtual Teaching in Student Learning at the Instituto Superior Tecnológico Pedro VilcapazaPeru]. Comuni@cción, 5(1), 14-21. Recuperado de: https://n9.cl/wkim9

Presidencia de la República de Ecuador. (2020). Decreto presidencial № 1017. [Presidential Decree No. 1017]. Recuperdo de: https://n9.cl/f3kkd 